\author{
Secretaria Municipal de \\ Saúde de São Paulo: Centro \\ de Controle e Prevenção de \\ Doenças da Coordenação \\ de Vigilância em Saúde \\ da Secretaria Municipal, \\ Supervisão de Vigilância em \\ Saúde Ipiranga, Unidade Básica \\ de Saúde "Almirante Delamare" \\ Secretaria de Estado da \\ Saúde de São Paulo: Divisão \\ de Doenças de Transmissão \\ Respiratória do Centro de \\ Vigilância Epidemiologia \\ "Prof. Alexandre Vranjac" da \\ Coordenadoria de Controle de \\ Doenças \\ Correspondência | Correspondence: \\ Secretaria de Estado da Saúde de São Paulo \\ Av. Dr. Arnaldo, $3511^{\circ}$ andar sala 135 \\ 01246-901 São Paulo, SP, Brasil
}

\section{Investigação de surto comunitário de doença meningocócica no Município de São Paulo, julho de 2007}

\author{
Inquiry of meningococcal disease \\ outbreak in São Paulo, July 2007
}

\begin{abstract}
A Neisseria meningitidis é um diplococo Gram-negativo que comumente coloniza o trato respiratório humano e causa doença endêmica ou epidêmica. As epidemias são mais freqüentes nos países em desenvolvimento. Poucas infecções podem levar à comoção social como acontece quando a doença meningocócica (DM) ocorre em uma comunidade. Uma das razões é a capacidade da $N$. meningitidis causar o óbito, em poucas horas, de um indivíduo previamente saudável.
\end{abstract}

Com base nas diferenças antigênicas dos seus polissacarídeos capsulares e de suas membranas protéicas externas, os meningococos podem ser classificados em sorogrupos, sorotipos, subtipos e imunotipos. Há 13 sorogrupos de $N$. meningitidis, porém apenas cinco (A, B, C, W135 e Y) estão mais freqüentemente associados à doença. A transmissão da DM ocorre pelo contato com gotículas de secreção do trato respiratório de portadores ou doentes.

As medidas preventivas contra a DM estão ainda limitadas principalmente ao diagnóstico e tratamento precoces e à prevenção de casos secundários, por meio de quimioprofilaxia. As vacinas polissacarídicas contra os meningococos A, C, Y e W135 têm sido usadas especialmente no controle de surtos e epidemias, pois são muito pouco imunogênicas em crianças menores de dois anos, não induzem memória imunológica e têm pouco ou nenhum efeito sobre o estado de portador. Um grande avanço na prevenção da DM foi o desenvolvimento recente das vacinas conjugadas contra o meningococo $\mathrm{C}$ que, além de eficazes em menores de dois anos, induzem a memória imunológica e diminuem as taxas de portadores, reduzindo a incidência da doença nos não-vacinados. Existe uma variedade de vacinas contra o meningococo do sorogrupo $\mathrm{B}$, porém o desenvolvimento de uma eficaz contra as diversas cepas existentes ainda é um desafio.

A incidência da DM pode variar de muito rara até 1.000 casos por 100.000 habitantes/ano. O sorogrupo A causa as maiores taxas e o sorogrupo B tem incidência mais baixa, porém pode causar epidemias de longa duração, com morbidade e mortalidade importantes. O sorogrupo C tem causado epidemias, clusters e surtos localizados, além de estar relacionado com o aumento da incidência em adolescentes e adultos jovens.

Para que se detecte um surto ou epidemia de DM é necessário que haja uma mudança do padrão usual, ou endêmico, de ocorrência da doença em determinado local. Segundo o Centers for Disease Control and Prevention (CDC), um surto comunitário de DM pode ser definido como a ocorrência de três ou mais casos, prováveis ou confirmados, em período menor ou igual a três meses, em residentes na mesma área geográfica, não comunicantes entre si, com taxa de ataque primária maior ou igual a dez casos por 100.000 habitantes.

No município de São Paulo, segundo dados do Sistema de Informação de Agravos de Notificação (Sinan), os coeficientes de incidência da DM apresentaram queda de 6,1 para 3,8/100.000 habitantes, de 1998 a 2003. Em 2004 observou-se um aumento; desde então, os coeficientes de incidência vêm se mantendo relativamente estáveis, em torno de 4,5/100.000 habitantes.

Houve aumento do percentual de casos com sorogrupo determinado de $26 \%$ em 1998 para $41 \%$ em 2006. En- 


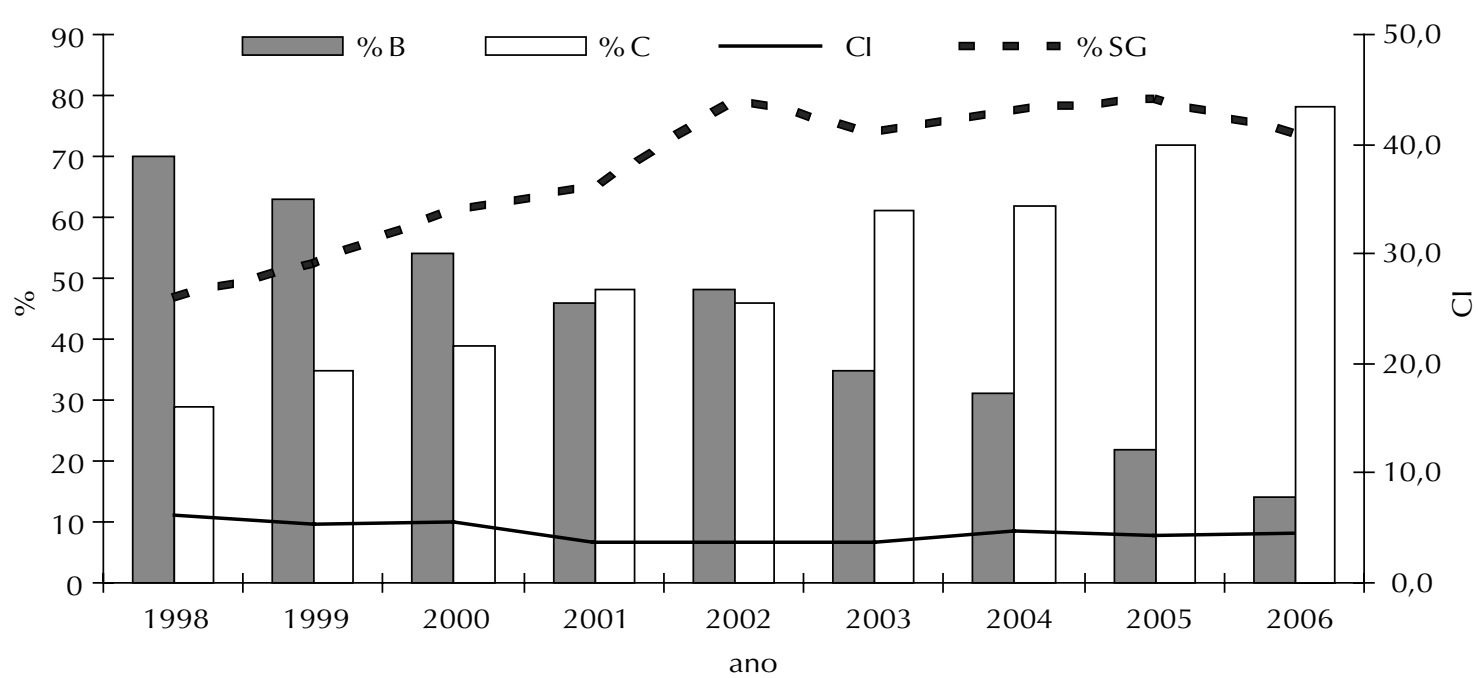

Fonte: SINANW e SINANNET.

Figura. Coeficiente de incidência (por 100.000 habitantes) de doença meningocócica segundo percentual sorogrupado (\%SG) e percentual de casos relacionados ao sorogrupo B e C. Município de São Paulo, 1998 a 2006.

tretanto, os relacionados ao sorogrupo C, que em 1998 representavam $29 \%$ dos casos sorogrupados, atingiram $78 \%$ em 2006; e houve queda dos relacionados ao sorogrupo B de $70 \%$, para 14\% (Figura). Desde 2003, dos casos relacionados ao sorogrupo $\mathrm{C}$ com identificação da cepa, mais de $40 \%$ correspondem à C:23:P1.14-6.

Além da mudança de sorogrupo predominante, observou-se também uma inversão da faixa etária mais afetada em 2005 e 2006, quando $52 \%$ e $53 \%$ dos casos, respectivamente, ocorreram em pacientes com cinco anos e mais.

A subprefeitura do Ipiranga, localizada na região Sudeste da Capital paulista, engloba a maior favela da cidade e segunda maior do País - Heliópolis; que se estende pelos distritos administrativos (DA) Sacomã e Ipiranga. Heliópolis é composta por 14 glebas, onde residem 125.000 habitantes, em uma área de quase um milhão de metros quadrados. O Ipiranga vem apresentando uma média de 7,4 casos de DM nos últimos cinco anos, com coeficientes de incidência que variaram de 4,2 em 2002 a 10,2 por 100.000 habitantes em 2006 (Tabela 1).

Para determinar ou descartar a ocorrência de um surto de DM na gleba $\mathrm{N}$ da comunidade Heliópolis, foi realizada uma investigação com conseqüente definição e viabilização de formas de controle adequadas. As etapas da investigação estão descritas a seguir.

Definição de caso: adotada a rotineiramente usada pela vigilância epidemiológica do município de São Paulo, descrita no Manual de Instruções Meningites - Critérios de Confirmação e Classificação, do Centro de Vigilância Epidemiológica "Prof. Alexandre Vranjac" (CVE). À definição foi acrescentado um novo critério de confirmação: o exame de reação em cadeia da polimerase em tempo real (PCR).

A doença meningocócica pode-se manifestar de várias formas, porém, para fins do sistema de vigilância epidemiológica, é classificada de acordo com o quadro clínico e os resultados dos exames laboratoriais em:

1. Meningococcemia - Paciente apresenta quadro toxiinfeccioso grave, com petéquias e/ou sufusões hemorrágicas, mas sem sinais e sintomas de meningite $\mathrm{e}$ sem alterações liquóricas que demonstrem a invasão do liquor pelo agente etiológico e os exames são:

- negativos ou não foram realizados ou

- bacterioscopia positiva no raspado da lesão de pele e/ou

- látex positivo no soro e/ou

- contraimunoeletroforese (CIE) positiva no soro e/ou

- PCR positivo no soro

- cultura positiva no soro

2. Meningite meningocócica - Paciente com sinais e sintomas de meningite sem a presença de petéquias e/ou sufusões hemorrágicas e alterações liquóricas que demonstrem a invasão do liquor pelo agente etiológico identificado ao menos pela bacterioscopia (a não ser que se utilize o critério vínculo epidemiológico). Ou que apresente ainda:

- látex positivo no liquor e/ou no soro e/ou 
- CIE positiva no liquor e/ou no soro e/ou

- PCR positivo liquor e/ou no soro

- cultura positiva no liquor e/ou no soro

3. Meningite meningocócica com meningococcemia - Paciente apresenta quadro clínico toxiinfeccioso agudo com sinais e sintomas de meningite, acompanhado de petéquias e/ou sufusões hemorrágicas e exames laboratoriais:

- negativos ou não foram realizados ou

- bacterioscopia positiva no raspado da lesão de pele e/ou no liquor e/ou

- látex positivo no liquor e/ou no soro e/ou

- CIE positiva no liquor e/ou no soro e/ou

- PCR positivo liquor e/ou no soro

- cultura positiva no liquor e/ou no soro

Fontes de dados: bancos de dados de notificação rápida de DM, Sinan, investigação de campo na gleba $\mathrm{N}$ da comunidade Heliópolis e Sistema de Informação de Atenção Básica.

População de estudo: casos de DM notificados entre 23 e 24 de julho de 2007, residentes na gleba $\mathrm{N}$ da comunidade Heliópolis.

\section{INVESTIGAÇÃO DOS CASOS}

Até o mês de julho de 2007, havia ocorrido apenas um caso de DM no DA Ipiranga relacionado ao sorogrupo C. Naquele mês foram notificados ao Centro de Prevenção e Controle de Doenças da Secretaria Municipal de São Paulo três casos de DM de pacientes residentes na gleba $\mathrm{N}$ da comunidade Heliópolis (Tabela 2).
Os pacientes foram internados em um dos hospitais municipais do município de São Paulo, onde foram colhidos os exames para confirmação diagnóstica, listados na Tabela 3. Os exames de CIE e PCR foram realizados pelo Laboratório de Meningites Bacterianas do Instituto Adolfo Lutz. Os demais foram realizados no laboratório do hospital; as culturas (sangue e liquor) foram negativas.

No dia 24 de julho foi realizada investigação de campo na gleba $\mathrm{N}$, na área de abrangência da Unidade Básica de Saúde (UBS) "Almirante Delamare", do Programa de Saúde da Família (PSF). Participaram da investigação: um técnico da Secretaria Municipal de Saúde de São Paulo, um técnico da supervisão de saúde do Ipiranga, o coordenador da equipe do PSF responsável pela região e dois agentes comunitários de saúde da mesma equipe.

Residem na gleba N, segundo os técnicos do PSF, 1.002 famílias, cadastradas em 2007, perfazendo um total de 3.351 habitantes, e aproximadamente 1.000 habitantes não cadastrados.

Não houve relato de qualquer contato entre os casos. Os comunicantes íntimos dos casos receberam quimioprofilaxia com rifampicina - os casos 1 e 2 no dia 23 e o caso 3 no dia 24 de julho. A taxa de ataque, calculada considerando-se a população cadastrada, foi de 89,52 por 100.000 habitantes.

No dia 27 de julho, após a identificação do sorogrupo C em amostras do caso 1 e 2, foi encaminhado relatório do para a Divisão de Doenças de Transmissão Respiratória, solicitando avaliação dos dados e liberação de vacinas para realização de bloqueio em menores de 20 anos.

Após avaliação técnica da Secretaria Estadual de SaúdeSP e do Ministério da Saúde, foi definida a idade de 14 anos como corte para a população a ser vacinada. As

Tabela 1. Coeficiente de incidência (Cl - por 100.000 habitantes) de doença meningocócica no distrito Ipiranga, segundo faixa etária. Município de São Paulo, 1998 a 2006.

\begin{tabular}{lrrrrrrrrrr}
\hline $\begin{array}{l}\text { Faixa } \\
\text { etária }\end{array}$ & \multicolumn{2}{c}{2002} & \multicolumn{2}{c}{2003} & \multicolumn{2}{c}{2004} & \multicolumn{2}{c}{2005} & \multicolumn{2}{c}{2006} \\
\hline$<1$ & $\mathrm{~N}$ & $\mathrm{Cl}$ & $\mathrm{N}$ & $\mathrm{Cl}$ & $\mathrm{N}$ & $\mathrm{Cl}$ & $\mathrm{N}$ & $\mathrm{Cl}$ & $\mathrm{N}$ & $\mathrm{Cl}$ \\
\hline 1 a 4 & 3 & 62,27 & 2 & 124,84 & 2 & 125,16 & 1 & 62,85 & 2 & 130,38 \\
5 a 9 & 02,27 & 1 & 20,81 & 6 & 125,21 & 2 & 41,91 & 3 & 65,19 \\
10 a 14 & 0 & 0,00 & 0 & 0,00 & 0 & 0,00 & 3 & 49,29 & 2 & 32,80 \\
15 a 19 & 0 & 0,00 & 1 & 16,02 & 1 & 16,58 & 1 & 17,17 & 0 & 0,00 \\
20 a 29 & 0 & 0,00 & 0 & 0,00 & 0 & 0,00 & 0 & 0,00 & 1 & 15,51 \\
30 a 39 & 0 & 0,00 & 0 & 0,00 & 0 & 0,00 & 2 & 12,55 & 0 & 0,00 \\
40 e + & 0 & 0,00 & 0 & 0,00 & 1 & 2,41 & 0 & 0,00 & 2 & 4,64 \\
\hline Total & 4 & 4,06 & 4 & 4,07 & 10 & 10,19 & 9 & 9,19 & 10 & 10,23 \\
\hline
\end{tabular}

Fonte: SINANW 
Tabela 2. Número de casos de doença meningocócica notificados segundo idade, sexo, data de início dos sintomas, forma clínica e evolução. Município de São Paulo, 2007.

\begin{tabular}{llllccc}
\hline Caso & Idade & Sexo & $1^{\circ}$ sint. & Sintomas & F. clínica & Evolução \\
\hline 1 & 9 anos & Fem. & $19 / 7$ & Febre, cefaléia, vômitos & MM & Alta \\
2 & 6 anos & Masc. & $20 / 7$ & Febre, cefaléia, vômitos, petéquias & MM+MC & Alta \\
3 & 1 ano & Fem. & $23 / 7$ & Vômitos, petéquias, coma & MC & Internado \\
\hline
\end{tabular}

MMM: meningite meningocócica; MC: meningococcemia

Tabela 3. Casos de doença meningocócica: resultado de exames. Município de São Paulo, 2007.

\begin{tabular}{lcccccccc}
\hline Caso & \multicolumn{4}{c}{} & \multicolumn{2}{c}{ Liquor } & \multicolumn{3}{c}{ Sangue } \\
& Leucócitos & Neutrófilos & Glicose & Proteína & CIE & PCR & CIE & PCR \\
\hline 1 & 8800 & 92 & 31 & 134 & neg & NmC & NmC & neg \\
2 & 24800 & 94 & $<10$ & 190 & neg & NmC & - & - \\
3 & 2 & - & - & - & neg & neg & neg & neg \\
\hline
\end{tabular}

CIE: contraimunoeletroforese

PCR: reação em cadeia de polimerase

vacinas chegaram à Capital paulista em 3 de agosto e a vacinação ocorreu no dia seguinte, realizada casa a casa. As crianças menores de um ano foram agendadas para receber a segunda dose em novembro de 2007.

As casas que se encontravam fechadas foram relacionadas para que o agente comunitário de saúde pudesse retornar e verificar se nelas havia menores de 15 anos, para serem encaminhados para vacinação.

Na ação foram mobilizados 50 profissionais de saúde, divididos em 16 equipes compostas por três membros: dois agentes comunitários de saúde, que conheciam os familiares e orientavam sobre a vacinação, e um auxiliar de enfermagem ou enfermeiro para aplicação e anotação das informações. Estavam presentes dois médicos para atender eventuais complicações, além dos profissionais que coordenaram a ação.

Considerando o número de residentes ausentes e casas fechadas no dia da vacinação, a equipe da Supervisão de Vigilância em Saúde do Ipiranga, responsável pela atividade, avaliou como superestimada a população fornecida pelo PSF. Além disso, as faixas etárias disponíveis nos dados não correspondiam às necessárias para os cálculos de vacinas e registro nas planilhas do Sistema se Informação de Avaliação do Programa de Imunização. Na Tabela 4 encontram-se as coberturas vacinais calculadas para a população cadastrada.

\section{COMENTÁRIOS}

É importante que se confirme rapidamente a ocorrência de um surto de DM quando casos suspeitos são notificados. Para tanto é preciso definir:

1. se a etiologia dos casos é meningocócica,
2. se a situação cumpre a definição de surto adotada pela vigilância local e

3. qual é o tamanho e a delimitação geográfica da área de ocorrência.

Em relação ao primeiro ponto, dois casos tiveram confirmação laboratorial, por PCR em tempo real. O terceiro caso foi confirmado por critério clínico, pois os exames colhidos foram negativos. Tratava-se de caso de meningococcemia, com evolução muito rápida, em criança de um ano de idade, que, após a recuperação do quadro inicial de choque e distúrbio de coagulação, necessitou debridamento em membros superiores, inferiores e região glútea. A criança permaneceu hospitalizada, com risco de amputação de pontas de artelhos do pé esquerdo.

Em relação à definição de surto, os três casos residiam na mesma gleba, não havendo evidência de qualquer contato entre eles, segundo pais e vizinhos. A taxa de ataque, em torno de 90/100.000 habitantes, mostrou risco elevado para esta população: aproximadamente

Tabela 4. Cobertura vacinal segundo faixa etária e população cadastrada, gleba N, comunidade Heliópolis. Município de São Paulo, 2007.

\begin{tabular}{lccc}
\hline Faixa etária & $\begin{array}{c}\text { População } \\
\text { cadastrada }\end{array}$ & Vacinados & $\begin{array}{c}\text { Cobertura } \\
(\%)\end{array}$ \\
\hline 2 a 11 meses & 52 & 35 & 67,31 \\
12 a 23 meses & 90 & 48 & 53,33 \\
2 a 4 anos & 271 & 145 & 53,51 \\
5 a 8 anos & 414 & 228 & 55,07 \\
9 a 12 anos & 261 & 163 & 62,45 \\
13 a 14 anos & 169 & 70 & 41,42 \\
\hline Total & 1.257 & 689 & 54,17 \\
\hline
\end{tabular}


30 vezes o coeficiente de incidência da DM na cidade de São Paulo de no primeiro semestre de 2007: 2,82/100.000 habitantes, com 284 casos notificados.

Apesar da gleba $\mathrm{N}$ fazer parte da comunidade Heliópolis, a investigação de campo permitiu a delimitação desta área, que é separada das outras glebas por meio de uma avenida.

Para determinar se as taxas epidêmicas da doença indicam a necessidade de vacinação, é indispensável que a maioria dos casos diagnosticados esteja relacionada a um sorogrupo prevenível por vacina. No surto aqui relatado, o sorogrupo $\mathrm{C}$ foi identificado por PCR (Tabela 3). Estudos confirmam a sensibilidade e especificidade do teste na identificação do agente etiológico da DM.

É necessária uma combinação de fatores para que ocorra uma epidemia, e dentre eles estão descritos: suscetibilidade da população à cepa prevalente e condições climáticas especiais, como estação seca e situação socioeconômica desfavorável. Segundo a Organização Mundial da Saúde (OMS), é difícil definir quais as medidas preventivas a serem adotadas quando populações pequenas apresentam altas taxas de incidência de DM. A quimioprofilaxia em massa não é uma medida recomendada para controlar epidemias. Entretanto, em surtos que envolvam populações limitadas, especialmente pelo sorogrupo B, a administração de quimioprofilaxia pode ser considerada. Deve-se avaliar não apenas o potencial para prevenção de novos casos, como também as condições logísticas, custo e potencial para desenvolvimento de resistência bacteriana. Quando escolhida, a quimioprofilaxia em massa deve ser administrada a toda população alvo ao mesmo tempo.

A vacinação da população de risco deve ser considerada se a taxa de ataque for maior que 10 casos por 100.000 habitantes. Porém, a taxa real de ataque, que se alcançada deve levar à decisão de vacinar, varia e devem ser considerados os seguintes fatores:

- $\quad$ se todos os casos foram notificados e se possíveis casos de DM nos quais a confirmação da etiologia ou do sorogrupo não foi possível;

- a duração esperada de risco elevado (por exemplo, se o surto ocorreu dois meses antes e não houve casos adicionais a vacinação dificilmente preveniria novos casos); e

- considerações logísticas e financeiras.

A comunidade Heliópolis reúne vários fatores favoráveis à ocorrência de um surto. A quimioprofilaxia em massa foi considerada inviável, devido à extensão da área e ao tamanho da população-alvo, impossibilitando a administração simultânea da droga conforme preconizado. Foi então considerada como melhor estratégia à vacinação, uma vez que se tratava realmente de um surto e desde o início dos sintomas do caso índice havia decorrido um período de oito dias.

Para a elaboração dos planos de vacinação foi preciso identificar as faixas etárias que apresentavam os maiores coeficientes de incidência da doença. Segundo a OMS, nos surtos de DM os casos ocorrem predominantemente entre indivíduos menores de 30 anos. Deve-se, entretanto, adequar a faixa etária de corte às possibilidades financeiras e de recursos humanos. Em Heliópolis não houve casos em maiores de nove anos.

Segundo dados do banco do Sinan, vem ocorrendo no município de São Paulo um aumento do número de casos de DM na faixa etária de cinco anos e mais, principalmente nas faixas de 10 a 29 anos. Todavia, os riscos de adoecimento para os menores de cinco anos são ainda bem maiores.

Em relação à letalidade, de 1998 a 2006 houve diminuição das taxas para os menores de 15 anos e de 20 a 29 anos. Na faixa de 15 a 19 anos, observou-se, no mesmo período, uma elevação de $14,3 \%$ para $28,0 \%$.

Considerando-se os coeficientes de incidência, as taxas de letalidade e, sua elevação nos últimos anos em algumas faixas etárias, foi sugerida a idade de 20 anos para o corte do grupo a ser vacinado.

Em parceria com Ministério da Saúde foi rediscutida a idade de corte e optou-se pela vacinação até os 14 anos, considerando-se o pequeno número de casos ocorridos nos últimos anos nas faixas etárias mais elevadas (Tabela 4). Os técnicos do Ipiranga e da UBS esclareceram e justificaram a estratégia aos líderes da comunidade Heliópolis, para que a vacinação se realizasse sem intercorrências.

Durante a vacinação, apesar da busca ter sido realizada casa a casa, e mesmo tendo sido feitas novas visitas às unidades fechadas na semana seguinte, não foi possível encontrar o número de habitantes cadastrados pela UBS. Houve, provavelmente, uma superestimação da população-alvo, o que levou a dificuldades nos cálculos de cobertura vacinal.

Em documento publicado em 10 de agosto de 2007, o Advisory Comittee on Immunization Practice (ACIP) do CDC de Atlanta (EUA) reviu as recomendações de maio de 2005 para incluir na vacinação de rotina nos Estados Unidos todas as pessoas de 11 a 18 anos, com uma dose da vacina conjugada tetravelente contra o meningococo. Manteve a recomendação de vacinação de 10 a 55 anos, para as pessoas que estão sob risco aumentado de adoecimento.

É difícil determinar o custo-benefício das vacinas contra o meningococo, uma vez que há inúmeros fatores envol- 
vidos. Além dos custos médicos dos episódios agudos, há outros como custos de seqüelas permanentes; custos dos surtos e epidemias para a sociedade, incluindo os das investigações, aquisição dos antibióticos para quimioprofilaxia, vacinas para bloqueio; ausências à escola e ao trabalho. Há, ainda, a dificuldade de incorporar aos benefícios o impacto da imunização de rebanho, dada a capacidade das vacinas conjugadas na diminuição da incidência da doença em pessoas não imunizadas. Ainda assim, estudos de custo-benefício realizados nos Estados Unidos sugerem que o custo por surto ou epidemia prevenido é relativamente alto, mas não tão diferente de outras intervenções já incorporadas.

No início dos anos 1990 alguns países desenvolvidos (Canadá, Inglaterra, Espanha, Irlanda e Grécia) apresentaram aumento da incidência da DM associado à emergência de novos clones de $N$. meningitidis, e em alguns locais houve necessidade de vacinação em massa ou de faixas etárias de risco.

Na cidade de São Paulo não se observou, até o momento, aumento dos coeficientes de incidência da DM. Porém, a alta percentagem de casos relacionados ao sorogrupo $\mathrm{C}$, a inversão do predomínio do número de casos para a faixa etária de cinco anos e mais, acrescidas da ocorrência de outro surto (em 2006, no DA Grajaú), indicam a necessidade de se intensificar a vigilância e discutir estratégias de controle da doença meningocócica. Para tanto, é imprescindível uma atuação integrada entre as áreas assistencial, de vigilância epidemiológica e laboratorial, a exemplo do que ocorreu nos surtos do Grajaú em 2006 e neste ano, na comunidade Heliópolis. 